\title{
Genetic Analysis and Discrimination of Sweet Cherry Cultivars and Selections Using Amplified Fragment Length Polymorphism Fingerprints
}

\author{
Lili Zhou, ${ }^{1}$ Frank Kappel, ${ }^{2}$ Cheryl Hampson, ${ }^{2}$ Paul A. Wiersma, ${ }^{2}$ and Guus Bakkeren ${ }^{2}$ \\ Agriculture and Agri-Food Canada, Pacific Agri-FoodResearch Centre, Summerland, BC VOH 1Z0, Canada
}

\begin{abstract}
AdDITIONAL INDEX WORDs. Prunus avium, similarity index, molecular marker, AFLP
Abstract. Amplified fragment length polymorphisms (AFLPs) were used to analyze the relationships between sweet cherry (Prunus avium L.) cultivars and selections from the breeding program at the Pacific Agri-Food Research Centre in Summerland, Canada. Six pairs of preselected primers were used for the analysis of a total of 67 cultivars and selections. Scoring the absence and presence of 118 polymorphic DNA fragments produced a unique binary code for each cultivar and selection. Two phylogenetic trees were constructed using these 118 polymorphic fragments, one tree for 55 related cultivars and selections from the Summerland breeding program and the other for 23 self-incompatible cultivars of differing origins. The reliability of AFLP DNA fingerprints was confirmed by correlating relationships revealed by AFLP profiles with known genetic relationships of some sweet cherry cultivars and by a blind test for cultivar identification. Results indicate that AFLP analysis is a good technique to evaluate genetic distance and relationships in a sweet cherry breeding population.
\end{abstract}

New cultivars of the sweet cherry (Prunus avium L.) have become increasingly important in the growing acreage of commercial planting in Canada as well as around the world. Replacing old cultivars such as Bing, Van, Lambert and Stella are a series of new late-ripening, self-fertile cultivars, including Lapins and Sweetheart developed at the Pacific Agri-Food Research Centre (PARC), Summerland, BC, Canada (Kappel and Lay, 1997). Managing these cultivars and the large resources associated with their development has become an increasing responsibility for a breeding program.

There is a strong demand for a rapid and reliable method of cultivar identification for Plant Breeder's Rights (PBR) registration and protection. Traditionally, the establishment of distinctness, uniformity and stability of varieties has been based on morphological descriptors and phenotypic characters in comparison with a full reference collection. However, morphological traits and horticultural characteristics are easily affected by environmental factors and become less discerning as the number of cultivars to be tested increases. In practice, full pedigree information on cultivars is usually not available, and morphological traits are not always appropriate because unrelated cultivars and closely related cultivars can display the same morphological characteristics. As an alternative to the morphological features, biochemical characteristics such as isozymes (Santi and Lemoine, 1990; Boskovic et al., 1997; Pashkoulov et al., 2000) have been useful for the determination of cultivar identities. However, the number of polymorphisms revealed by isozyme analysis is limited in sweet cherry and not all sweet cherry cultivars tested can be discriminated (Tobutt and Boskovic, 1996). With the development of molecular techniques and the increase of data processing power, DNA markers have become the most reliable source of information for characterizing genotypes and identifying cultivars. Such DNA fingerprinting methods include the use of restriction fragment length polymorphism (RFLP) (Tanksley et

Received for publication 22 Oct. 2001. Accepted for publication 5 June 2002. Contribution number 2142 for Pacific Agri-Food Research Centre, Agriculture and Agri-Food Canada . We thank Bingtian Wang, Rob Linning, and Anita Quail for technical assistance and John W. Hall for advice on statistical analysis.

${ }^{1}$ Postdoctoral fellow; to whom reprint requests should be addressed; e-mail zhoul@EM.AGR.CA.

${ }^{2}$ Research scientist. al., 1989) or random amplified polymorphic DNA (RAPD) fragments (Gerlach and Stosser, 1998; Shimada et al., 1999; Williams et al., 1990), simple sequence repeat (SSR) (Boritzki et al., 2000; Cantini et al., 2001) and AFLP (Vos et al., 1995). RFLP and SSR techniques need knowledge of the DNA sequences of the species being tested and the development of RFLP and SSR markers is expensive and time-consuming (Boritzki et al., 2000; Vos et al., 1995). A combination of RFLP analysis on PCRamplified chloroplast DNA has been used to find relatedness between some wild populations and cultivars of $P$. avium (Mohanty et al., 2001). RAPD analysis using 200 primers of which only 25 were informative could not separate 18 sweet cherry cultivars (Gerlach and Stosser, 1998). AFLP fingerprinting has been shown to reveal a relatively high degree of polymorphism in sweet cherry using radioisotope labeled primers (Boritzki et al., 2000; Struss et al., 2001; Tavaud et al., 2001). Boritzki et al. (2000) discussed the difficulties of using radioisotope labeled primers such as no proper size calling method on x-ray film. We wanted to examine the use of fluorescent labeled AFLPs. Very limited information is available from previous AFLP studies, such as appropriate primer selection. Fingerprints for cultivars and selections from the PARC Summerland breeding program were also lacking (Boritzki et al., 2000; Struss et al., 2001).

The purposes of this study were to 1) examine the possibility of using fluorescent labeled AFLPs to evaluate the genetic diversity within the breeding program, and 2) develop AFLP fingerprints for identification of cultivars and new selections of sweet cherries.

\section{Materials and Methods}

Plant Material. DNA fingerprinting: Fresh leaves of 67 sweet cherry cultivars and selections were collected from the fields of the PARC, Summerland, B.C., Canada. Leaf samples (leaves from two to five plants for each selection or cultivar were mixed) were frozen in liquid $\mathrm{N}_{2}$ and stored at $-70{ }^{\circ} \mathrm{C}$ until used.

Cultivar identification test: In a blind experiment, a single branch of each of four selections (of which one was cultivar Staccato), was brought to the laboratory together with one identified branch of cultivar Staccato. Branches were incubated in water at $23^{\circ} \mathrm{C}$ for 
2 weeks in the early Spring 2001. Young leaves were collected and frozen in liquid $\mathrm{N}_{2}$ and stored at $-70{ }^{\circ} \mathrm{C}$ until used.

AFLP PROCEDURE. The method for genomic DNA isolation from leaf tissue of 67 of the cultivars and selections was as follows. One gram of frozen tissue was ground with mortar and pestle with liquid $\mathrm{N}_{2}$, transferred to a centrifuge tube containing $6.5 \mathrm{~mL}$ of extraction buffer [100 mм Tris, $\mathrm{pH} 8.0 ; 50$ mм EDTA; $500 \mathrm{~mm} \mathrm{NaCl} ; 1.25 \%(\mathrm{w} / \mathrm{v})$ SDS; $2 \%$ (w/v) polyvinylpyrrolidone-40 (PVP); $0.38 \%$ (w/v) $\mathrm{NaHSO}_{3}$ ] and incubated at $65^{\circ} \mathrm{C}$ for $1 \mathrm{~h}$. After incubation, $2.5 \mathrm{~mL} 5 \mathrm{~m}$ of KOAc was added and the mixture was placed on ice for $20 \mathrm{~min}$. The homogenate was centrifuged at $5000 g_{\mathrm{n}}$ for $20 \mathrm{~min}$ at $4{ }^{\circ} \mathrm{C}$ and the supernatant was transferred to a clean tube containing $4.5 \mathrm{~mL}$ of cold $\left(-20^{\circ} \mathrm{C}\right)$ isopropanol. Genomic DNA was precipitated at $-20^{\circ} \mathrm{C}$ for 1 to 2 $h$. The DNA was then either pelleted in a centrifuge tube or if visible collected with a pipet and transferred to a microfuge tube containing $1 \mathrm{~mL}$ of purifying buffer (70\% EtOH, $0.3 \mathrm{~m} \mathrm{NaOAc}$ ). After centrifugation, the DNA pellet was washed with $70 \%$ ethanol, centrifuged again and air dried. The DNA was dissolved in $300 \mu \mathrm{L}$ double distilled $\mathrm{H}_{2} \mathrm{O}$. One unit RNase-A was added to the solution to digest contaminating RNA at $37^{\circ} \mathrm{C}$ for $20 \mathrm{~min}$. DNA was further purified once using a phenol-chloroform extraction method and ethanol precipitation. Genomic DNA isolation from buds for the cultivar identification test was performed as described in the DNeasy Plant Mini Kit (Qiagen, Mississauga, Ont.).

AFLP procedures were performed essentially as described by Vos et al. (1995) with minor modifications. DNA was digested with $E c o R I$ and $M s e I$ restriction enzymes. After $1 \mathrm{~h}$ digestion at $37^{\circ} \mathrm{C}, 5 \mathrm{pmol} E c o R I$ adaptor (5'-CTCGTAGCTGCGT ACC $/ 5$ 'AATTGGTACGCAGTCTAC) and 50 pmol Mse I adaptor (5'GACGATGAGTCCT GAG/5'-TACTCAGGACTCAT) and ligation mixture were added and incubation at $37^{\circ} \mathrm{C}$ was continued for an additional $3 \mathrm{~h}$. Ten microliters of digestion-ligation mixture was run on a $1.2 \%$ agarose gel in $1 \times \mathrm{TBE}$ buffer (Tris, Borate, EDTA) to verify complete digestion and conversion. Sixty microliters of double distilled water was added to the remaining 40 $\mu \mathrm{L}$ of solution to create the template stock solution.

Preamplification and AFLP analyses were performed using the Selective Amplification Start Up kit for small genome (Applied Biosystems, Foster City, Calif.). The primer sequences used for the first selective amplification (prePCR) were $E c o R I$ plus A or T and Mse I plus C (Table 1). The reactions were performed on a GeneAmp 2400 PCR system (Applied Biosystems). Half the volume of the PCR reaction was analyzed on a $1.5 \%$ agarose gel (in $1 \times$ TBE buffer ) and the remaining half was diluted to a final $200 \mu \mathrm{L}$ with $10 \mathrm{~mm}$ Tris buffer (pH 8.0). A 1.5 to $3 \mu \mathrm{L}$ aliquot of this diluted PCR mix was used as a template for the second selective amplification with fluorescent labeled primers. Primer combinations used are listed in Table 1. The PCR reaction was performed on a 96-well TwinBlock System (Ericomp, San Diego, Calif.) using the following touch-down profile: cycle 1:2 min at $94{ }^{\circ} \mathrm{C}, 30 \mathrm{~s}$ at $65^{\circ} \mathrm{C}$, then $72{ }^{\circ} \mathrm{C}$ for $2 \mathrm{~min}$; cycle 2 to $9: 30 \mathrm{~s}$ at 94 ${ }^{\circ} \mathrm{C}, 30 \mathrm{~s}$ at $64{ }^{\circ} \mathrm{C}$ lowering the annealing temperature each cycle by 1 degree, 2 min at $72{ }^{\circ} \mathrm{C}$; then 23 cycles of $30 \mathrm{~s}$ at $94{ }^{\circ} \mathrm{C}, 30 \mathrm{~s}$ at $56^{\circ} \mathrm{C}, 2 \mathrm{~min}$ at $72{ }^{\circ} \mathrm{C}$; and a final extension cycle of $30 \mathrm{~min}$ at $60{ }^{\circ} \mathrm{C}$.

For analysis, $2 \mu \mathrm{L}$ of each of three differently labeled fluorescent AFLP products (6-FAM, JOE, and NED) were combined with $0.4 \mu \mathrm{L}$ ROX labeled $500 \mathrm{bp}$ size standard in $19 \mu \mathrm{L}$ formamide. These dyes fluoresce at different wave lengths and show up as blue, green, yellow, and red, respectively in the data scans. This allows for mixing the products and analysis in a single run (Applied Biosystems). The mixture was heated at $94^{\circ} \mathrm{C}$ for $3 \mathrm{~min}$, cooled on ice, and subjected to capillary gel electrophoresis on an automated genetic analyzer using $47 \mathrm{~cm} \times 50 \mu \mathrm{M}$ capillaries and $\mathrm{POP}_{4}$ polymer solution (Prism ABI 310; Applied Biosystems). Typical analysis parameters were injection for 5 to $10 \mathrm{~s}$ at $15 \mathrm{kV}$ and a $27 \mathrm{~min}$ run at $13 \mathrm{kV}$ and $60{ }^{\circ} \mathrm{C}$.

AFLP procedures were replicated by starting from different DNA extractions and were performed randomly using several cultivars of sweet cherry (Stella, Royal Ann, Dawson, Viscount, Sandra rose, NJ 1599, Van, and Sonata). PCR amplification and AFLP analysis of each cultivar was performed at least twice. When any DNA sample gave ambiguous results, DNA extraction, template preparation, and AFLP analysis were repeated until results were consistent.

Data ANALYSIS. Sizing and normalization of the bands (corresponding to single strand DNA molecules in nucleotide) on the output from an ABI 310 genetic analyzer was done with the aid of the internal size standard and the GeneScan 3.1 software package (Applied Biosystems). Alignment of the fragments in the scans was done with the GenoTyper 2.5 software package (Applied Biosystems). Polymorphic peaks were scored visually in all 67 tested samples. To be informative, polymorphic peaks should be present or absent in at least two cultivars out of the 67 studied. Polymorphisms were scored as 1 (presence of fragment peak) or 0 (absence of fragment peak). The binomial data set was then entered into a spreadsheet. Parsimony analysis of the data sets in the phylogenetic analysis using parsimony (PAUP) soft-

Table 1. List of primer combinations used for testing polymorphisms in sweet cherry. EcoR I primers labeled at the 5'-end with FAM , JOE, or NED as indicated. The underlined primers were used for fingerprinting of 67 sweet cherry cultivars and selections.

\begin{tabular}{|c|c|c|c|c|c|}
\hline \multicolumn{2}{|c|}{ EcoR I = 5'-GACTGCGTACCAATTC- } & \multicolumn{4}{|c|}{ Mse I = 5'-GATGAGTCCTGAGTAA- } \\
\hline & \multicolumn{2}{|c|}{ JOE labeled } & \multicolumn{2}{|c|}{ NED labeled } \\
\hline$\overline{E c o R}$ I plus & MseI plus & EcoR I plus & MseI plus & EcoR I plus & Msel plus \\
\hline $\mathrm{AC}$ & CTA & $\mathrm{AG}$ & CTA & TT & CTA \\
\hline $\mathrm{AC}$ & CAA & AG & $\mathrm{CAG}$ & TT & $\mathrm{CAC}$ \\
\hline$\underline{\mathrm{AC}}$ & CAG & $\mathrm{AG}$ & CTG & TT & CTG \\
\hline$\overline{\mathrm{TG}}$ & $\overline{\mathrm{CAT}}$ & AG & CAT & $\overline{\mathrm{TT}}$ & $\overline{\mathrm{CTC}}$ \\
\hline TG & CTA & $\underline{\mathrm{AA}}$ & $\underline{\mathrm{CTG}}$ & TT & CAT \\
\hline TG & CAA & $\overline{\mathrm{AA}}$ & $\overline{\mathrm{CAC}}$ & AT & CTG \\
\hline TG & CAG & TA & CTA & $\underline{\mathrm{AT}}$ & CTT \\
\hline $\mathrm{TC}$ & $\mathrm{CAG}$ & $\mathrm{TA}$ & CAT & $\overline{\mathrm{AT}}$ & $\overline{\mathrm{CAG}}$ \\
\hline $\mathrm{TC}$ & CTC & TA & CAT & AT & CTA \\
\hline $\mathrm{TC}$ & CTA & $\mathrm{TA}$ & CTG & AT & CAT \\
\hline
\end{tabular}


ware version 4b (Swofford, 1999) was used as a phylogenetic inference method. Heuristic searches with random step-wise addition and 10 replications were performed (MAXTREES set at 200). The bootstrap analysis was done using the full heuristic search option in PAUP 4b or using dollop parsimony in Phylip (Felsenstein, 1989) (consensus tree after $10 \times 100$ bootstrap replications).

\section{Results}

POLYMORPHISMS DETECTED BY AFLP ANALYSIS ON SWEET CHERRY. Prescreening of primer combinations for pairs that would produce polymorphisms was performed using four related cultivars and selections (Skeena, Sonata, 13S-21-01 and SPC 243) and the related species peach (Prunus persica L.) as the outgroup. Thirty primer combinations representing three different fluorescent dyes were randomly selected (Table 1). The resulting profiles demonstrated that primer pairs with this level of specificity $(E c o R$ $I+$ two bases and Mse $I+$ three bases) generated satisfactory profiles with a manageable number of well-separated bands for these small-sized plant genomes of $\approx 265$ (peach) and $338 \mathrm{Mbp}$ (sweet cherry; Arumuganathan and Earle, 1991). It also showed that amplifications were very selective. For example, peach ('Field heaven') and sweet cherry ('Salmo') shared fewer than $30 \%$ of bands in the profiles generated with primer pairs $E c o R I$ $+A C / M s e I+C A G$ and EcoR $I+A A / M s e I+C T G$ (data not shown), while $>90 \%$ of bands were shared when comparing any pair of sweet cherry genotypes. Primer combinations that produced an AFLP fingerprint with a fair number of normally distributed and well-separated bands between 40 and $500 \mathrm{bp}$ and that gave the largest number of polymorphic bands were selected to test 67 cherry cultivars (Table 1). To obtain complete confidence in the profiles, replications were compared and their patterns verified. Anomalies were observed for several samples due to DNA quality (from old leaves) which led initially to a higher number of polymorphisms. Further replications of freshly prepared templates corrected these errors. One hundred and eighteen polymorphic bands out of a total of 625 bands from six selected primer pairs were obtained, with an average of 20 informative markers per primer pair. Fewer than $19 \%$ of the scored bands were polymorphic, showing that the overall genetic diversity among the tested cherry cultivars was relatively low.

GENETIC DISTANCE AND RELATIONSHIP BETWEEN THE CULTIVARS AND SELECTIONS. Most cultivars and selections could be distinguished by a single set of primers, with the exceptions of closely related cultivars and mutant cultivars generated through irradiation. A binary matrix was generated by comparing the 67 AFLP profiles generated with the six primer pairs and scoring 1 for the presence or 0 for the absence of a particular fragment. Pairwise distance between cultivars and selections was calculated using the PAUP $4 \mathrm{~b}$ program. The mean marker differences which took into account both the positive and negative matches of polymorphic bands, ranged from 0.11 to 0.53 . The total marker difference ranged from 13 to 62 among the 67 cultivars and selections.

We wanted to understand better the genetic relationships among the cultivars and selections from the Summerland breeding program and see whether the AFLP profiles correlated with known genetic relationships. Therefore, phylogenetic relationships were calculated using the binomial data set and dendrograms were constructed for 56 related cultivars and selections from Summerland (Fig. 1A). In addition, 23 cultivars of differing origins were compared (Fig. 1B). The parentage and origin of tested cultivars and selections were included to evaluate the representation and correlation with the AFLP markers (Fig. 1A and B). For comparison, a UPGMA analysis was also performed on 56 selections and a phylogenetic tree was generated (data not shown). No outgroup was apparent in the tested cultivars, indicating that these sweet cherries have a very narrow genetic background.

Cultivar identification test. After the inventory of AFLP profiles for the 67 cultivars and selections had been established, the reliability of AFLP DNA fingerprinting was examined by a cultivar identification test. Could the AFLP method distinguish a specific cultivar from within a group of unknowns? Field samples from four cultivars were brought to the laboratory with random numbered labels along with a standard (in this case the cultivar Staccato). Sample identities were not revealed until after analysis had been completed. Among the five tested DNA samples, two selections (\#457 and \#589) were found to be very close to 'Staccato' and two selections (\#194 and \#725) were easily distinguished from this cultivar by comparing their AFLP profiles (Table 2). Accession \#457 had exactly the same profile as 'Staccato' and \#589 was identified as cultivar Sweetheart based on comparison with AFLP profiles in the data base. Accession \#194 was similarly identified as selection '13S-13-09'. Accession \# 725 ('Kordia' synonym 'Attica') did not match any of the previous profiles which is consistent because it was not included in the original inventory.

\section{Discussion}

AFLP ANALYSIS. Ideally, a fingerprinting technique should require no prior knowledge in terms of DNA sequence analysis (e.g., for oligonucleotide primer synthesis), or characterization of DNA probes (Vos et al., 1995). With little sequence information and few probes available for sweet cherry, AFLP was found to be an appropriate method for rapidly developing fingerprint profiles. Six combinations of primer pairs labeled with different fluorescent markers were used to generate fingerprints of 67 cultivars and selections of sweet cherry. These combinations generated reproducible profiles of 50 to 100 well-separated fragments between 40 and 500 bp whereby one or two primer pairs were already sufficient to distinguish many of the 67 sweet cherry cultivars. Only four different fluorescent labeled primers were needed. In addition, three AFLP reactions labeled with different fluorescent dyes (6-FAM, JOE and NED) could be pooled with a ROX-labeled internal size standard for separation and detection in the same electrophoresis run. This procedure improved efficiency and reduced experimental cost. Including an internal size standard not only allowed accurate size determination but also provided a reference for trouble shooting. The failure to detect a normal band pattern due to an unsuccessful AFLP$\mathrm{PCR}$ reaction or electrophoresis run was easily distinguished by looking at the standard curve and intensity of the internal standard.

AFLP is a very sensitive and robust method to perform DNA fingerprinting. However, several key procedures must be carefully controlled for reproducibility of the AFLP profile. These include the extraction of high-quality total genomic DNA, complete digestion of this DNA by restriction endonucleases, efficient adapter ligation during template preparation and the use of optimal buffer and primer dilutions for the PCR reaction.

The use of AFLP fingerprints for phylogenetic analyses is a relatively new technology. Although the GeneScan and GenoTyper 


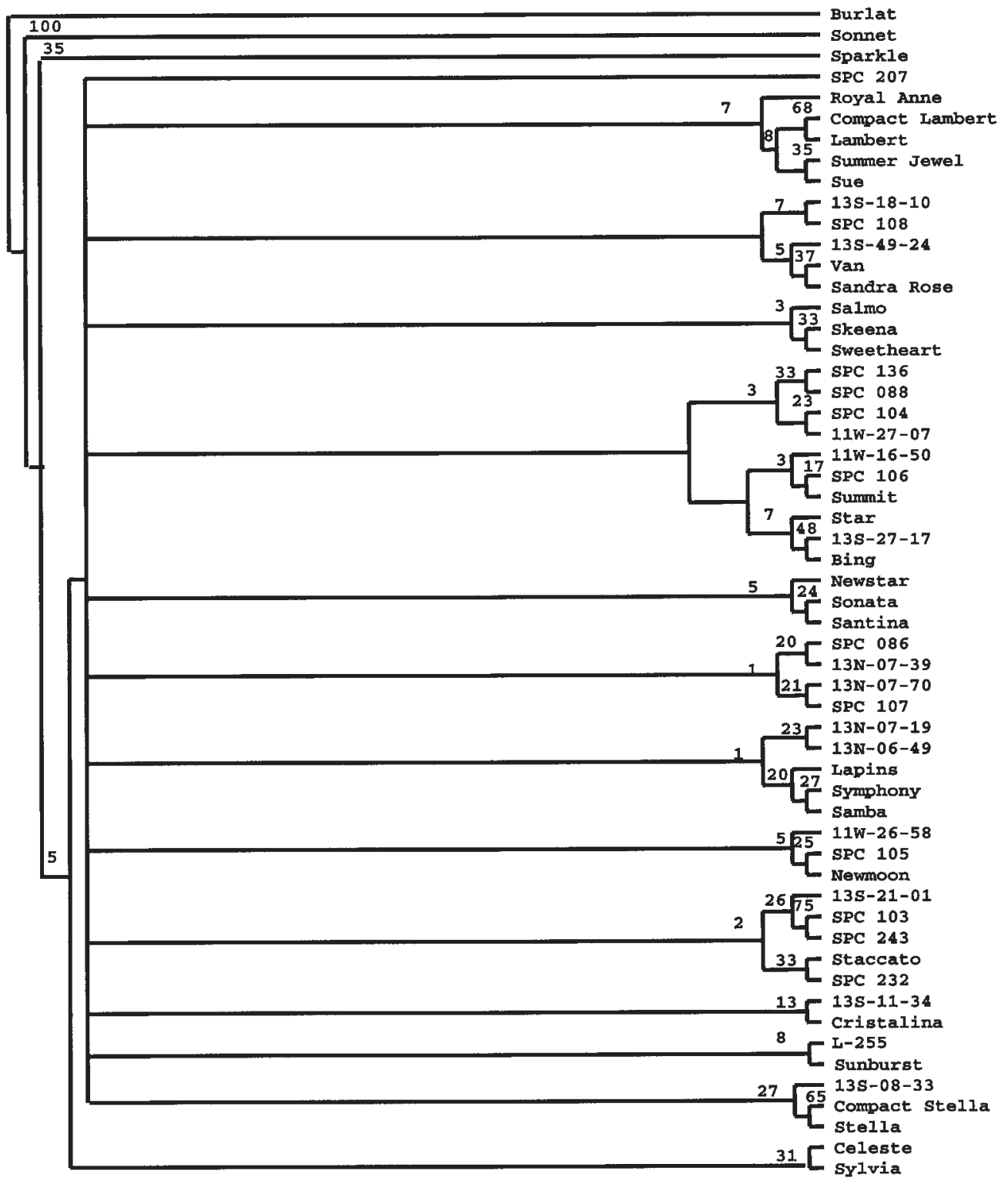

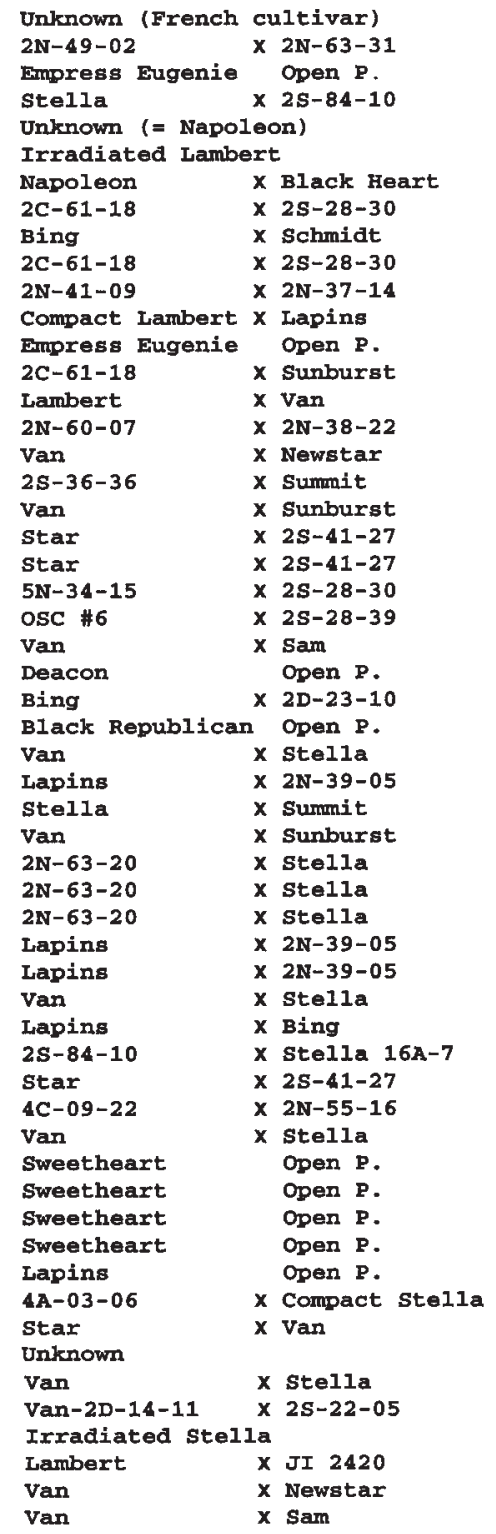

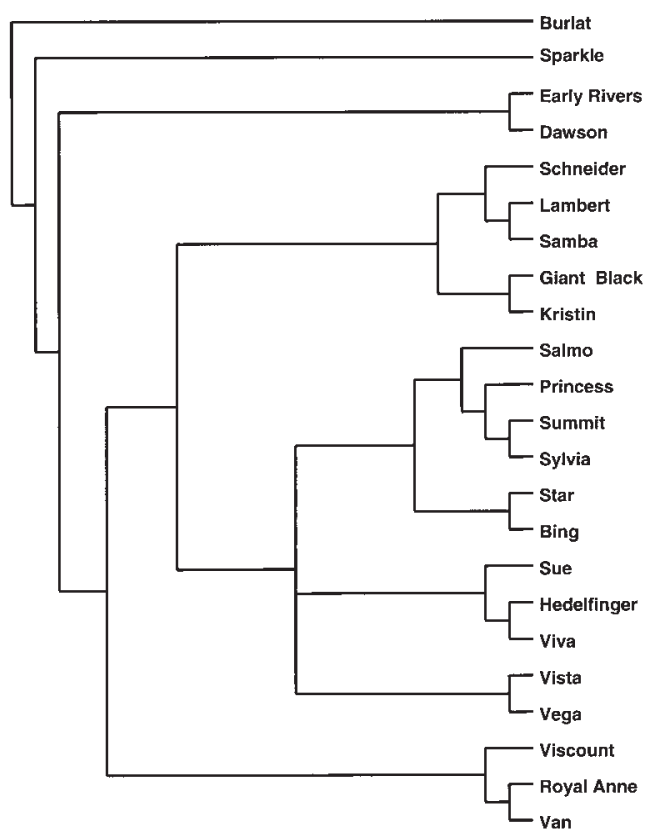

Unknown (France)

Empress Eugenie open $P$.

Early Purple open P.

Unknows (Australia)

Mapoleon $\times$ Black Heart

25-84-10 x Ste11a (Summerland, BC)

mperor F. $X$ Gil peck (USA)

Lanbert $x$ Van (Sumer 1 and BC)

Onknown

Van $x$ sam (Summerland BC)

Van $X$ Sam (Sumerland BC)

Deacon open $P$. (Summerland $\mathrm{BC}$ )

Black Republican open P. (USA)

Bing $x$ Schnidt (Sumerland BC)

Unknown (Germany)

HedeIfinger $x$ windsor (Vineland oN)

Hecelfinger $x$ Victor (Vineland oN

Bing $x$ victor (Vireland ON)

(Bedel $x$ Bing) $x$ (Hedel $x$ Bing) (Vineland oN)

Unknown (= Napoleon)

Empress Eugenie open P. (Summerland BC)
Fig. 1. Phylogenetic relationships among cultivars from the Summerland breeding program and 23 cultivars of different origins. (top) Consensus tree of 55 Summerland sweet cherry selections and related cultivars, plus cultivar Burlat as a forced outgroup. The tree was constructed using the Dollop (Phylip) computer program with random addition options (1000 bootstrap replications) based on 118 AFLP markers. The numbers to the left or above the node indicate the percentage of times the node was found after $10 \times 100$ bootstrap replications. (bottom) Consensus tree of 23 sweet cherry cultivars of different origins constructed with the Dollop (Phylip) computer program using the random addition options (1000 bootstrap replications) based on 118 AFLP markers. Parentage of each cultivar or selection was indicated on the right for evaluation of AFLP markers. Open $\mathrm{P} .=$ open pollinated, unknown male parentage. 
softwares (Applied Biosystems) provide excellent sizing and annotation of fragments to help in analyzing the data, they are less adept for automatic scoring of polymorphisms in a large data set. All profiles had to be visually scored or verified.

A major advantage of AFLP analysis over techniques using RFLP-PCR and possibly SSRs, is the larger number of fragments it can produce and hence higher degree of polymorphisms it can reveal. AFLP analysis therefore gives a high resolution, which is necessary when studying populations with a low degree of genetic variability such as inbred sweet cherry. Mohanty et al. (2001) who used a RFLP-PCR technique on chloroplast DNA, achieved only a low level of resolution in a wild population of sweet cherry. Cantini et al. (2001) achieved a good level of discrimination using SSRs, but was studying tetraploid sour cherry $(P$. cerasus $\mathrm{L}$.) ground cherry $(P$. fruticosa $\mathrm{L}$.) and their hybrids and needed 10 primers. In preliminary experiments using three pairs of SSR primers, we could only distinguish five selections and cultivars in a family of 16 inbred lines from our breeding program (L. Zhou, unpublished data). SSRs seem therefore unsuitable for distinguishing between the selections and cultivars in our Summerland collections.

LOW DEGREE OF GENETIC DIVERSITY IN CULTIVATED SWEET CHERRY WORLDWIDE. Sweet cherry has a relatively small genome of $\approx 680 \mathrm{Mbp}$ or $0.7 \mathrm{pg}$ per diploid genome (Arumuganathan and Earle, 1991). A low degree of polymorphism in sweet cherry was also seen by Gerlach and Stosser (1998) who reported similarity indices ranging from 0.83 to 0.98 and Shimada et al. (1999) who reported similarity indices ranging from 0.51 to 0.98 . Both of these studies used RAPD markers to identify sweet cherry cultivars. We found that $90 \%$ of the AFLP DNA fingerprints were similar within the investigated 67 cultivars and selections (data not shown) and even those cultivars from different origins shared many of the same markers (Table 3). The maximum pair-wise distance between two cultivars in our tests was 0.53 . The distances between 'Irradiated Stella' and 'Stella', 'Irradiated Lambert' and 'Lambert' are 0.11 and 0.19 , respectively. The polymor-

Table 2. Results for the cultivar identification test. Binary code revealed by scoring of AFLP fragments are derived from the primer pairs indicated for five tested DNA samples, where presence (1) or absence (0) of a particular fragment in base pairs (top) is noted. One of the four unidentified samples (\#725, \#194, \#457 and \#589) was the cultivar Staccato, namely sample \#457.

\begin{tabular}{|c|c|c|c|c|c|c|c|c|c|c|c|c|c|c|c|c|c|c|c|c|c|}
\hline \multirow[b]{3}{*}{ Sample } & \multicolumn{21}{|c|}{ Primer pairs [size (bp)] } \\
\hline & \multicolumn{3}{|c|}{ AC-CAG } & \multicolumn{5}{|c|}{ C-CAA } & \multicolumn{9}{|c|}{ AA-CAC } & \multicolumn{4}{|c|}{ TT-CTG } \\
\hline & 108 & 207 & 342 & 126 & 234 & 429 & 445 & 486 & 120 & 208 & 211 & 236 & 237 & 263 & 264 & 362 & 398 & 66 & 156 & 349 & 400 \\
\hline Staccato & 0 & 0 & 0 & 0 & 1 & 1 & 0 & 0 & 1 & 0 & 0 & 1 & 0 & 1 & 1 & 0 & 0 & 1 & 0 & 0 & 1 \\
\hline$\# 725$ & 0 & 1 & 0 & 1 & 0 & 0 & 1 & 1 & 1 & 0 & 0 & 0 & 1 & 0 & 1 & 1 & 0 & 1 & 1 & 1 & 1 \\
\hline \#194 & 0 & 1 & 1 & 1 & 1 & 0 & 0 & 0 & 0 & 1 & 1 & 1 & 0 & 0 & 1 & 1 & 1 & 0 & 0 & 1 & 0 \\
\hline \#457 & 0 & 0 & 0 & 0 & 1 & 1 & 0 & 0 & 1 & 0 & 0 & 1 & 0 & 1 & 1 & 0 & 0 & 1 & 0 & 0 & 1 \\
\hline \#589 & 1 & 0 & 0 & 0 & 1 & 1 & 0 & 0 & 1 & 0 & 0 & 1 & 0 & 1 & 0 & 0 & 0 & 1 & 0 & 0 & 1 \\
\hline
\end{tabular}

Table 3. Similarity indices (simple match coefficient) computed using 118 polymorphic AFLP markers generated by 6 primer combinations for 23 cultivars analysed (compare Fig 1B). 1 = Early Rivers, $2=$ Dawson, $3=$ Schneider, $4=$ Lambert, $5=$ Samba, $6=$ Giant Black, $7=$ Kristin, $8=$ Salmo, $9=$ Princess, $10=$ Summit, $11=$ Sylvia, $12=$ Star, $13=$ Bing, $14=$ Sue, $15=$ Hedelfinger, $16=$ Viva, $17=$ Vista, $18=$ Vega, $19=$ Viscount , $20=$ Royal Ann, 21 = Van, 22 = Sparkle, 23 = Burlat.

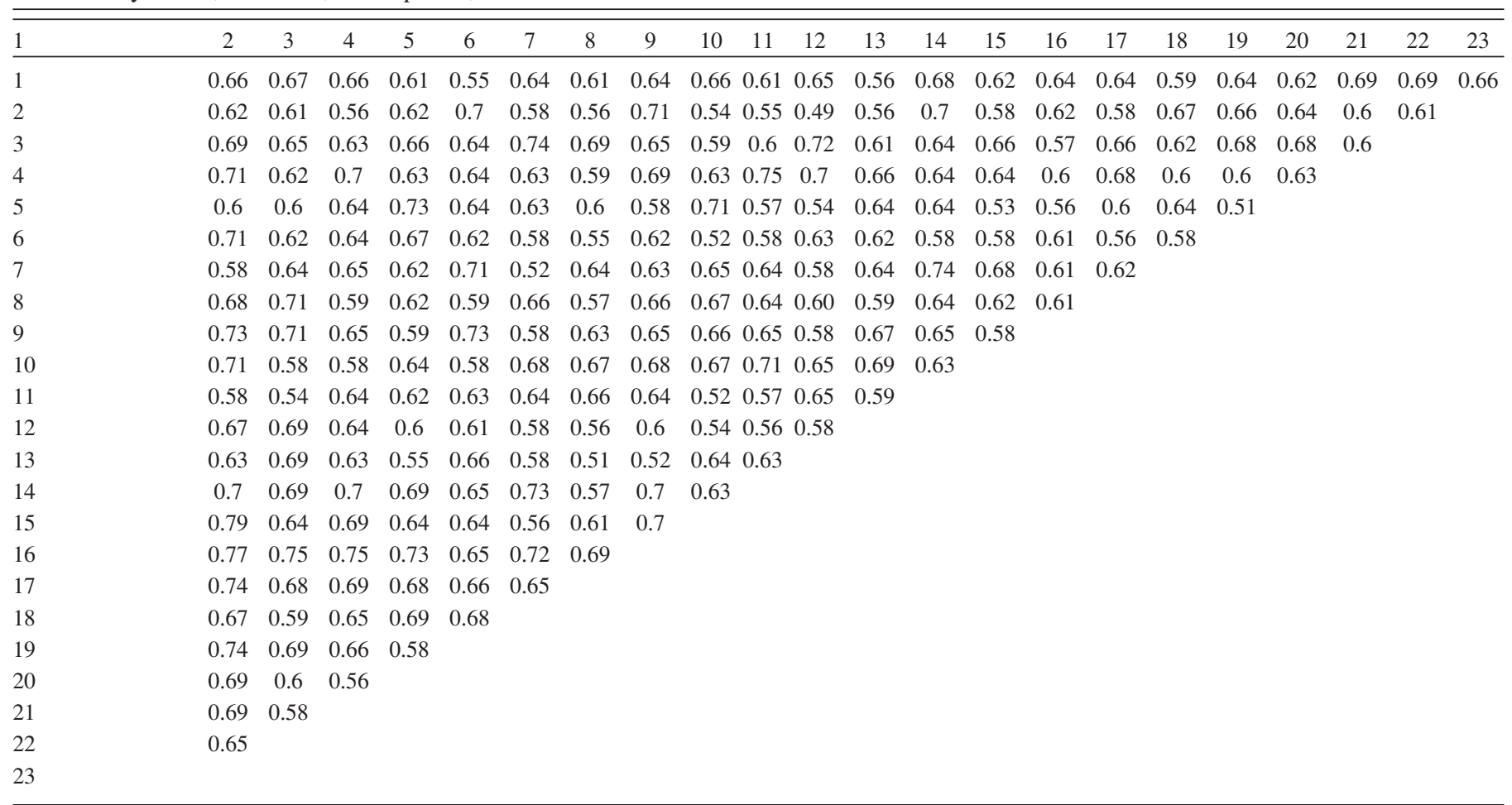


Table 4. Comparison of a subset of AFLP profiles from cultivars Van, Sunburst and their presumed offspring, SPC 088. AFLP fragments in base pairs were derived from primer pairs as indicated. Score is 1 (present) or 0 (absent) for each particular DNA fragment.

\begin{tabular}{|c|c|c|c|c|c|c|c|c|c|c|c|c|}
\hline \multirow[b]{2}{*}{ Sample } & \multicolumn{12}{|c|}{ Primer pairs [size (bp)] } \\
\hline & 137 & 228 & 73 & 306 & 349 & 400 & 292 & 340 & 362 & 198 & 308 & 326 \\
\hline Sunburst & 1 & 0 & 1 & 0 & 1 & 1 & 0 & 0 & 0 & 1 & 1 & 1 \\
\hline Van & 1 & 0 & 1 & 0 & 1 & 1 & 0 & 0 & 0 & 1 & 1 & 1 \\
\hline
\end{tabular}

phic rate of $19 \%$ we found is similar to the $17 \%$ reported by Boritzki et al. (2000). This group also performed AFLP analysis but used 10 pairs of primers and the restriction enzyme sites Hind III and Mse I. However, the same group reported a much higher genetic distance $(0.32$ to 0.98$)$ between cultivars and selections when EcoR I and Mse I enzyme sites were used (Struss et al. 2001). These authors did not present a very detailed description of the procedures they followed or the primer combinations they used, making a directed comparison to our data difficult.

Most previous molecular marker work in sweet cherry has focused on the separation of tested cultivars or selections (Boritzki et al., 2000; Cantini et al., 2001; Mohanty et al., 2001; Struss et al., 2001; Tavaud et al., 2001). It is not clear how the genetic relationships revealed by AFLP data match with the known genetic background of cultivated sweet cherries. In other words, the reliability of genetic diversity revealed by AFLP markers has not been intensively studied. The purpose of drawing two separate phylogenetic trees for Summerland related cultivars/selections (Fig. 1A) and 23 worldwide cultivars (Fig. 1B) respectively, was to see if any subgroup or historic relationship exists between different cultivars. As mentioned earlier, no subgroup was found within tested cultivars (Fig. 1A and B). The limited genetic variability of sweet cherry revealed by our AFLP analysis is consistent with the known genetic background of cultivars and selections from the Summerland, B.C., and Ontario breeding programs (Fig. 1A and B). For instance, selections SPC 103, SPC 243, 13S-21-01 and 'Staccato' are four open-pollinated seedlings of 'Sweetheart', and share $95.2 \%$ to $97.8 \%$ of the AFLP markers. In another example, selections SPC 107, 13N-07-39 and 13N-0770 are all progeny of the parents 2 N-63-20 ('Bing' $x$ 'Stella') $x$ 'Stella' (Fig. 1A) and accordingly fall into the same subbranch. 'Vista', 'Vega', and 'Viva', along with their parent 'Hedelfinger', are also close to each other in the phylogenetic tree. 'Summit' and 'Sylvia' also fall into the most close position due to the same genetic background (Fig. 1B). The low frequency of polymorphisms among the subbranches (Fig. 1A) suggests that the variation in genetic background among the tested selections is very small.

The cultivar identification test demonstrated that verification could be easily performed by including a reference sample at the same time. No DNA variation was found in different samples of the same cultivar or selection when extraction and AFLP conditions were identical. However, exact identification in the absence of a reference sample becomes more difficult when little genetic variation exists, as exemplified in our test between cultivar Sweetheart and its open-pollinated seedling 'Staccato' (Table 2). A much larger data set generated with more primer pairs would be needed to construct a more robust phylogenetic tree and to better separate closely related selections.

FingerPrint DATA CAN CORRECT PEDIGREes. Selections SPC 088 and SPC 086 are two recorded progeny of the cross 'Van' $\mathrm{X}$
'Sunburst'. However, their AFLP profiles do not seem to resemble the profile of either 'Van' or 'Sunburst'. 'Sunburst' is one of the progeny of 'Van', which is reflected in a low relative genetic distance of 0.296 between the two. SPC 088 is separated from 'Van' and 'Sunburst' by genetic distances of 0.381 and 0.423 , respectively, while SPC 086 is separated from 'Van' and 'Sunburst' by genetic distances of 0.288 and 0.364 , respectively. The distance between SPC 088 and SPC 086 was 0.347 while the distances between SPC 088 and other selections ranged from 0.27 to 0.52 . More importantly, there are seven AFLP fragments present in both 'Van' and 'Sunburst' but missing in the profile of SPC 088 and five markers present in SPC 088 but absent in both 'Van' and 'Sunburst' (Table 4). Apparently, SPC 088 is not likely to be the offspring of 'Van' and 'Sunburst'. This result is consistent with data revealing the S-allele composition (L. Zhou, unpublished data). From the position of SPC 088 on Fig. 1A, SPC 088 may have the same parentage as SPC 136 or SPC 104 and 11W-27-07.

APPLICATIONS OF AFLP IN SWEET CHERRY BREEDING. Our data demonstrate that AFLP fingerprints can distinguish cultivars of sweet cherry even in a population with limited genetic diversity. Therefore, AFLP is useful as an identification tool. In addition, the polymorphisms detected in the profiles from two parents and their progeny can potentially be used to construct a genetic map. If any of the fragments were found to be linked to a specific morphological or physiological character (e.g., fruit color, date of maturity, self-fertility or disease resistance), they could be used for marker-assisted selection. This would significantly reduce breeding time and increase efficiency, because markers can be used at the seedling stage, avoiding the need to wait until the new genotypes start to fruit. Unique profiles also open the possibility for testing unknown or open-pollinated crosses for parental backgrounds and for aiding in Plant Breeder's Rights issues.

\section{Literature Cited}

Arumuganathan, K. and E.D. Earle. 1991. Nuclear DNA content of some important plant species. Plant Mol. Biol. Rpt. 9:208-218.

Boritzki, M., J. Plieske, and D. Struss. 2000. Cultivar identification in sweet cherry (Prunus avium L.) using AFLP and micro-satellite markers. Acta Hort. 538:505-510.

Boskovic, R., K.R. Tobutt, and F.J. Nicoll 1997. Inheritance of isoenzymes and their linkage relationships in two interspecific cherry progenies. Euphytica 93:129-143.

Cantini C, A.F. Iezzoni, W.F. Lamboy, M. Bortizki, and D. Struss. 2001. DNA fingerprinting of tetraploid cherry germplasm using simple sequence repeats. J. Amer. Soc. Hort. Sci. 126:205-209.

Felsenstein J. 1989. PHYLIP-phylogeny inference package (version 3.2). Cladistics 5:164-166.

Gerlach, H.K. and R. Stosser 1998. Sweet cherry cultivar identification using RAPD-derived DNA fingerprints. Acta Hort. 468:63-69.

Kappel, F. and W. Lay. 1997. Sweet cherry breeding in Canada from the early 1900s to 1994. Fruit Var. J. 51:233-238. 
Mohanty A., J.P. Martin, and I. Aguinagalde. 2001. Chloroplast DNA study in wild populations and some cultivars of Prunus avium L. Theor. Appl. Genet. 103:112-117.

Pashkoulov, D.T., K.R. Tobutt, and R. Boskovic. 2000. Comparison of isoenzymes in Prunus avium separated by two different electrophoretic techniques. Plant Breeding 119:153-156.

Santi, F. and M. Lemoine 1990. Genetic markers for Prunus avium L. II. Clonal identifications and discrimination from $P$. cerasus and $P$. cerasus $x$ P. avium. Ann. Sci. For. 47:219-227.

Shimada T., T. Shiratori, H. Hayama, K. Nishimura, M. Yamaguchi, and M. Yoshida 1999. Genetic diversity of cherries characterized by random amplified polymorphic DNA (RAPD) analysis. J. Jpn. Soc. Hort. Sci. 68:984-986.

Struss, D., M. Bortiziki, K. Glozer, and S.M. Southwick. 2001. Detection of genetic diversity among populations of sweet cherry (Prunus avium L.) by AFLPs. J. Hort. Sci. Biotechnol. 76:362-367.
Swofford, D.L. 1999. PAUP: Phylogenetic analysis using parsimony. version 4.0 b2. Sinauer Associates, Sunderland, Mass.

Tanksley, S.D,. N.D. Young, A.H. Paterson, and M.W. Bonierbale. 1989. RFLP mapping in plant breeding: New tools for an old science. Bio/Technology 7:257-264.

Tavaud, M., A. Zanetto, F. Santi, and E. Dirlewanger. 2001. Structuration of genetic diversity in cultivated and wild cherry varieties using molecular markers. Acta Hort. 546:263-269.

Tobutt, K.R. and R. Boskovic. 1996. A cherry gene database. Acta Hort. 410:147-153.

Vos P., R. Hogers, M. Bleeker, M Reljans., T. van de Lee, M. Hornes, A. Frijters, J.Pot, J. Peleman, M. Kuiper and M.Zabeau. 1995. AFLP: A new technique for DNA fingerprinting. Nucleic Acids Res. 23:4407-4414.

Williams, J.G.K., A.R. Kubelik, K.J. Livak, J.A. Rafalski, and S.V. Tingy. 1990. DNA polymorphisms amplified by arbitrary primers are useful as genetic markers. Nucleic Acids Res. 18:6531-6535. 